\title{
Sistem Keamanan Ganda Sepeda Motor dengan Fingerprint dan GPRS Berbasis Arduino untuk Peningkatan Keamanan
}

\author{
Bartholomeus Danar Agus Setya ${ }^{1}$, Masduki Zakarijah ${ }^{2}$ \\ ${ }^{1}$ Program Studi Teknik Elektronika Fakultas Teknik Universitas Negeri Yogyakarta \\ ${ }^{2}$ Program Studi Pendidikan Teknik Elektronika Fakultas Teknik Universitas Negeri Yogyakarta \\ E-mail: danaragus74@gmail.com
}

\begin{abstract}
Preventive measures when motorcycle theft occurs. Fingerprint is a biometric which can be used for unique and stable authentication. Attempted to prevent motorcycle security systems from being able to move. Therefore, if there is an indication of theft, the system response is to turn off the motorcycle system. This article describes several things including: (1) the design and realization of the fingerprint sensor and GPRS design for motorcycle safety systems; and (2) fingerprint and GPRS sensor performance in motorcycle safety systems. The development stages consist of needs analysis, identification of needs, design and completion (realization of design and testing). The test results show: (1) the fingerprint sensor in the security system is an accurate authentication; GPRS can send messages on the motorcycle owner's android phone, and the numeric code can send the exact numeric code; and (2) the overall performance of the system works according to the expected function with good performance. Preventive efforts to steal motorbikes can be pursued through a developed security system. Further development is related to a security system to support repressive efforts, particularly in relation to tracking motorbikes that have been stolen by thieves. Motorcycle safety systems in the future can be combined between preventive and repressive measures. Optimization of smart phones can be an alternative to the telecommunications equipment used.
\end{abstract}

Keywords: Arduino MEGA2560, Fingerprint, GPRS, Motorcycle Security

\begin{abstract}
ABSTRAK
Tindakan preventif tindakan pencurian sepeda motor perlu dilakukan. Sidik jari merupakan salah satu biometric yang dapat digunakan untuk otentikasi yang unik dan stabil. Sistem keamanan sepeda motor diusahakan mencegah pencuri untuk dapat berpindah. Oleh karena itu, sistem tersebut apabila diketahui indikasi pencurian, maka respon sistem adalah mematikan sistem sepeda motor. Artikel ini mendeskripsikan beberapa hal diantaranya: (1) perancangan dan realisasi perancangan sensor sidik jari dan GPRS pada sistem pengaman sepeda motor; dan (2) unjuk kerja sensor sidik jari dan GPRS pada sistem pengaman sepeda motor. Tahapan pengembangan terdiri atas analisis kebutuhan, identifikasi kebutuhan, perancangan dan penyelesaian (realisasi perancangan dan pengujian). Hasil pengujian menunjukkan: (1) sensor sidik jari pada sistem pengaman menjadi otentitakasi yang akurat; GPRS dapat mengirim pesan pada ponsel android pemilik sepeda motor, dan kode kumerik dapat mengirimkan kode angka yang tepat; dan (2) kinerja keseluruhan sistem bekerja sesuai fungsi yang diharapkan dengan kinerja yang baik. Upaya preventif pencurian sepeda motor dapat diupayakan melalui sistem keamanan yang dikembangkan. Pengembangan selanjutnya terkait sistem keamanan untuk mendukung upaya represif, khususnya terkait pelacakan sepeda motor yang dirampas pencuri. Sistem pengaman sepeda motor ke depan dapat dikombinasikan antara upaya preventif dan represif. Optimalisasi ponsel pintar dapat menjadi alternatif perangkat telekomunikasi yang digunakan.
\end{abstract}

Kata kunci: Arduino MEGA2560, Fingerprint, GPRS, Keamanan motor

\section{PENDAHULUAN}

Kecenderungan pertumbuhan kendaraan bermotor menghadirkan dampak negatif, yaitu menyebabkan kemacetan, polusi udara, kecelakaan, dan tundaan-tundaan [1]. Beberapa hal yang menyebabkan pengguna memilih sepeda motor sebagai moda transportasi yang digunakan adalah praktis, efisien dan memiliki mobilitas yang lebih efektif [2]. BPS menyebutkan bahwa di tahun 2018 terdapat sepeda motor sejumlah 120.101.047 [3]. Jumlah sepeda motor yang banyak memperbesar 
kemungkinan terjadinya tindak pidana pencurian sepeda motor [4]. Terdapat beberapa pengelompokkan kejahatan, salah satunya adalah kejahatan pencurian tanpa penggunaan kekerasan. Pada setiap tahun, kelompok kejahatan tersebut yang terjadi paling banyak, yang didominasi kejahatan pencurian biasa dan pencurian kendaraan. Kejahatan terhadap Hal Milik/ Barang berupa curanmor di tahun 2018 adalah 27731 kasus [5]. Adanya banyak perilaku kejahatan curanmor perlu mendapat perhatian dari berbagai pihak. Diperlukan beberapa upaya dari berbagai pihak untuk menekan jumlah kejahatan curanmor tersebut.

Pencurian merupakan jenis tindak pidana yang sering terjadi. Keresahan dan ketidaknyamanan dalam masyarakat merupakan dampak negatif dari salah satu penyakit masyarakat berupa tindak pidana pencurian. Terkait hal tersebut maka dibutuhkan pengaman untuk mengantisipasi kejahatan curanmor tersebut [6]. Usaha menekan tindakan pencurian yang dilakukan pihak kepolisian yaitu: (1) preemtif berupa internalisasi nilai dan norma yang baik dalam diri seseorang, sehingga menghilangkan unsur faktor dan niat pencurian; (2) preventif berupa pencegahan terjadinya kejahatan; dan (3) represif pemberantasan dan penanggulangan kejahatan [7]. Pihak kepolisian lebih mengedepankan tindakan preventif dalam upaya penanggulangan tindakan tersebut [4]. Upaya pencegahan dinilai lebih baik daripada tindakan pemberantasan dikarenakan efisiensi tenaga, waktu dan biaya jika dibandingkan dengan melakukan tindakan pencarian, penyelidikan, penangkapan, atau pengejaran maupun penyidikkan. Tindakan preventif yang dimaksud adalah mencegah terjadinya pencurian.

Masyarakat memiliki kewaspadaan dan sikap kehati-hatiang yang masih kurang menjadi salah satu penyebab terjadinya curanmor [8]. Perhatian terhadap keamanan dan keselamatan sepeda motor yang dimiliki kurang disadari masyarakat dan sistem keamanan di tempat prakir yang lemah merupakan beberapa hal yang menjadi kendala dalam upaya preventif [4]
Kelalaian korban merupakan salah satu penyebab kejahatan curanmor. Penguna sebaiknya memarkir kendaraan bermotor ditempat umum yang aman, dengan penerangan cukup dan dapat dijangkau atau diawasi dengan kamera pengawas. Beberapa langkah antisipatif mencegah terjadinya kejahatan pencurian kendaraan bermotor adalah: (1) tidak memarkir kendaraan di sembarang tempat; (2) memastikan telah mencabut dan menyimpan kunci sepeda motor dengan aman; (3) tidak meninggalkan barang berharga; (4) pemasangan kunci ganda atau tambahan; (5) penerapan teknologi side stand switch; (6) menempelkan tanda pengenal sebagai tanda karakteristik sepeda motor; dan (7) memasang alarm [9].

Kelalaian pemilik, kurangnya tambahan alat pengaman, lemahnya peraturan perparkiran, keamanan lokasi yang belum memadai, hasil penjualan sangat menguntungkan, kecilnya risiko yang ditimbulkan, mudahnya transaksi penjualan ataupun pemasaran kendaraan bermotor dari hasil kejahatan dan alat untuk melakukan kejahatan yang mudah didapatkan menjadi permasalahan-permasalahan yang mendukung pencurian sepeda motor. Permasalahan tersebut harus segera diatasi baik dari pihak pemerintah maupun masyarakat serta peran mahasiswa untuk menekan bertambahnya angka kriminalitas terhadap pencurian sepeda motor. Pemberantasan habis kejahatan sulit dilakukan, akan tetapi kejahatan dapat dicegah [6]. Pemasangan sistem pengaman sepeda mator dinilai menjadi alternatif usaha preventif kejadian curanmor.

Terdapat beberapa metode sistem keamanan sepeda motor yang telah dikembangkan. Sistem keamanan sepeda motor dengan penggunaan sistem otentikasi, diantaranya adalah: (1) apabila pengenalan sidik jari gagal, maka sistem akan memberikan notifikasi pada ponsel pintar [10]; (2) apabila ID Tag sesuai maka relay terhubung untuk menyalakan mesin sepeda motor [11]; (3) apabila Tag ID tidak sesuai, maka alarm berbunyi, led merah menyala dan SMS terkirim ke ponsel pemilik [12]; (4) apabila username dan 
password salah serta ponsel pintar tidak dapat terhubung maka alarm menyala [13]; (5) apabila kata sandi yang dimasukkan tidak sesuai maka memicu alarm dan mesin motor tidak dapat dinyalakan [14]; dan (6) apabila tidak memasukkan password pada keypad atau mengirim pesan teks dari nomor pengguna maka aliran listrik dari aki terputus, kemudian menyalakan alarm dan mengirim pesan berisi informasi lokasi ke nomor pengguna [15]. Sistem keamanan sepeda motor dengan sensitifitas indikasi gerakan tertentu seperti: (1) apabila ada gerakan tertentu ada notifikasi ke ponsel pintar, pengguna menyalakan alarm dari ponsel pintar [16]; dan (2) apabila salah satu sensor mencapai nilai (jarak dan ketinggian) tertentu, maka akan mengunci sistem dan menyalakan alarm [17]. Pengamanan sepeda motor pada saat terparkir dan perampasan di jalan yaitu dengan memiliki pengaman saat mode parkir dan mode jalan. jika ada perilaku yang membahayakan sepeda motor, sistem mengirim SMS. Saat terjadi perampasan, pengguna mematikan motor melalui aplikasi di ponsel pintar [18]. Sistem keamanan dengan posisi sepeda motor terampas: (1) memutus listrik pada kontak melalui perintah SMS, kemudian mengirimkan koordinat lokasi motor melalui SMS [19]; dan (2) ketika terputusnya koneksi wifi terputus, maka sepeda motor tidak bisa dihidupkan [20]. Sistem keamanan sepeda motor yang mengutamakan fungsi dari kunci sepeda motor yang dapat mengunci stang sepeda motor agar tidak dapat digerakan dimana-mana. Sistem keamanan sepeda motor tersebut dapat diatasi dengan memiliki kunci yang sama dengan pemilik motor. Penggunaan remot pada sistem keamanan, remot digunakan untuk menyaklar sumber tegangan dan motor dapat dinyalakan serta dikunci stang dengan menggunakan remot. Tetapi sistem keamanan remot mudah untuk dipelajari sehingga alat keamanan ini masih bisa diatasi oleh pencuri.

Artikel ini membahas sistem kendaraan bermotor pada ranah upaya preventif. Poin utama tindakan preventif pada pencurian sepeda motor adalah pencuri tidak dapat menyalakan kendaraan bermotor yang diambil paksa. Hal tersebut diimplementasikan pada sistem keamanan yang dikembangkan. Berpijak dari berbagai sistem keamanan sepeda motor sebelumnya, sistem otentikasi merupakan sistem yang dipilih sebagai upaya preventif pencurian kendaraan bermotor. Biometrik sebagai teknologi yang menganalisis data biologis berperan penting pada penggunaannya di sistem keamanan. Keunggulan biometrik adalah keunikan dan kestabilannya sebagai pengenal [21]. Salah satu contoh dari biometrik adalah sidik jari (fingerprint). Penggunaan sidik jari lebih mudah daripada penggunaan tag ID. Penggunaan tag ID memungkinkan pengguna lupa atau hilang [11]. Dilain pihak, jumlah pengguna ponsel pintar di Indonesia diperkirakan mencapai 81,87 juta pengguna pada tahun 2020 [22]. Terdapat banyak aplikasi bermanfaat yang dapat dikembangkan dan dimaksimalkan pemanfaatannya di ponsel pintar. Salah satu fitur pada ponsel pintar adalah SMS. Artikel ini mendeskripsikan pengembangan sistem keamanan sepeda motor yang memanfaatkan sidik jari sebagai otentikasi serta dapat menyalakan alarm dan memberikan notifikasi ke pengguna melalui SMS apabila percobaan otentikasi gagal. Sistem keamanan cerdas (Smart Security) ini diharapkan dapat meningkatkan keamanan sepeda motor di Indonesia.

\section{METODE}

Metode yang digunakan untuk mengembangkan sistem keamanan ganda pada sepeda motor menggunakan sensor Fingerprint dan GPRS berbasis Arduino adalah metode rancang bangun. Bobbe et al. membandingkan prosedur pengembangaan produk dari akademisi, organisasi dan standar profesional, serta dari studio desain. Secara umum tahapan pengembangan produk adalah: analisis (analyse), penentuan (define), perancangan (design) dan penyelesaian (finalise) [23]. Penentuan atau pendefinisian merupakan tahap sintesis pada tingkat abstrak, sedangkan desain adalah sintesis solusi yang kongkrit. Pada artikel ini tahapan 
analisis digunakan untuk menganalisis kebutuhan kinerja produk yang dikembangkan. Dari hasil analisis tersebut, dilanjutkan dengan identifikasi kebutuhan secara spesifik yang dilakukan perancangan perangkat keras dan perangkat lunak. Pada akhir, tahapan penyelesaian dilakukan yaitu pembuatan serta pengujian alat. Tahapan rancang bangun bangun sistem keamanan tersaji pada Gambar 1.

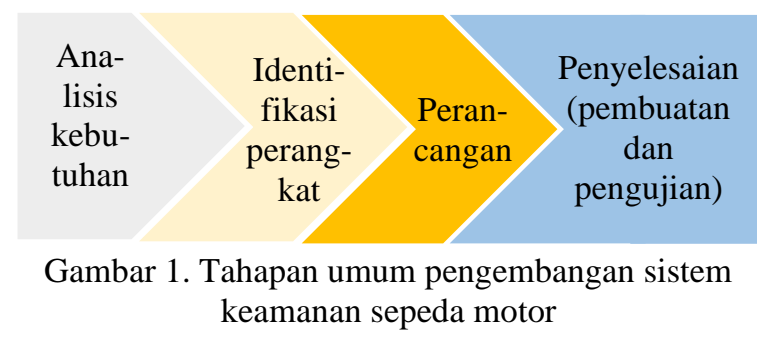

Sistem keamanan cerdas yang dimaksud menunjukkan kinerja bahwa sepeda motor akan dapat dinyalakan dengan melakukan otentikasi menggunakan sidik jari pemilik motor. Jika tidak menggunakan sidik jari pemilik sepeda motor, sepeda motor tidak dapat dinyalakan. Sistem tersebut disertai GPRS dengan menggunakan modul sim 8001 yang dapat membuat perangkat di sepeda motor terhubung dengan ponsel pemilik sepeda motor. Apabila terdapat percobaan otentikasi sidik jari yang gagal berulangkali dari seseorang, maka alarm akan berbunyi dan pesan singkat (SMS) terkirim pada ponsel pemilik sepeda motor.

\section{HASIL DAN PEMBAHASAN}

Analisis kebutuhan pengembangan sistem ini yaitu dibutuhkan: (1) komponen yang dapat digunakan untuk mendeteksi variable sidik jari; (2) komponen kendali yang mampu memproses hasil pendeteksian sidik jari dan tindak lanjut dari pendeteksian; (3) komponen yang mampu mengirim dan menerima SMS berbasis mikrokontroler; (4) komponen yang dapat memberikan keluaran bunyi; dan (5) komponen untuk menghidupkan atau mematikan sepeda motor dan alarm. Hasil analisis kebutuhan tersebut kemudian diidentifikasikan secara spesifik. Pada bagian masukan, sistem keamanan yang dikembangkan membutuhkan komponen yang dapat membaca sidik jari manusia. Sensor sidik jari digunakan untuk membaca sidik jari pemilik sepeda motor. Sistem keamanan yang dikembangkan dapat menyimpan 10 macam sidik jari. Selain Sensor sidik jari sistem juga membutuhkan komponen yang dapat mengirim data berupa angka. Sistem Kode Numerik dapat mengirim data angka 0 sampai dengan 9 serta tombol up, down, dan ok. Sistem Kode Numerik dipilih karena dapat digunakan untuk merancang tombol- tombol yang sesuai kebutuhan pengembangan.

Pada bagian proses, alat ini membutuhkan komponen yang dapat mengolah data dari masukan yang akan dikirim ke bagian keluran. Arduino Mega 2560 digunakan sebagai pengendali utama yang akan melakukan pemrosesan data dan keputusan pengendali sistem data. Arduino Mega 2560 dipilih sebagai pengendali utama karena memiliki 54 pin digital yang dapat digunakan untuk jalur input maupun output yang sifatnya dapat diprogram ulang. Pada bagian output, sistem membutuhkan komponen yang dapat menampilkan data input sidik jari sensor Fingerprint atau angka Sistem Kode Numerik. LCD 16 X 2 digunakan sebagai penampil data input yang menerima olahan data dari proses Arduino Mega 2560. LCD 16 X 2 dipilih karena memiliki 16 kolom serta 2 baris yang sudah mencukupi kebutuhan. Sistem membutuhkan suatu modul yang dapa mengirim data ke android yaitu SIM800L. SIM800L digunakan untuk mengirim pesan " Peringtan!!! Ada yang mencoba menghidupkan sepeda motor dan salah memasukkan kode PIN", ke android pemilik sepeda motor. Sistem juga memerlukan alarm sebagai keluaran yang mengeluarkan bunyi. Sistem ini membutuhkan 2 relay untuk mensaklar alarm serta kontak sepeda motor. Relay yang digunakan memiliki daya tahan sampai dengan 10A. Aplikasi yang dipilih dalam pemrograman sistem adalah Arduino IDE, karena pada dasarnya aplikasi Arduino IDE dirancang untuk mempermudah penggunaan Arduino itu sendiri. 
Tahapan berikutnya adalah perancangan. Perangkat keras pada sistem ini terbagi menjadi 2 macam yaitu blok panel kontrol serta blok modul komunikasi. Langkah awal perancangan alat ini yaitu dengan merancang skema rangkaian. Gambar 2 menunjukkan skema rangkaian perangkat kendali.

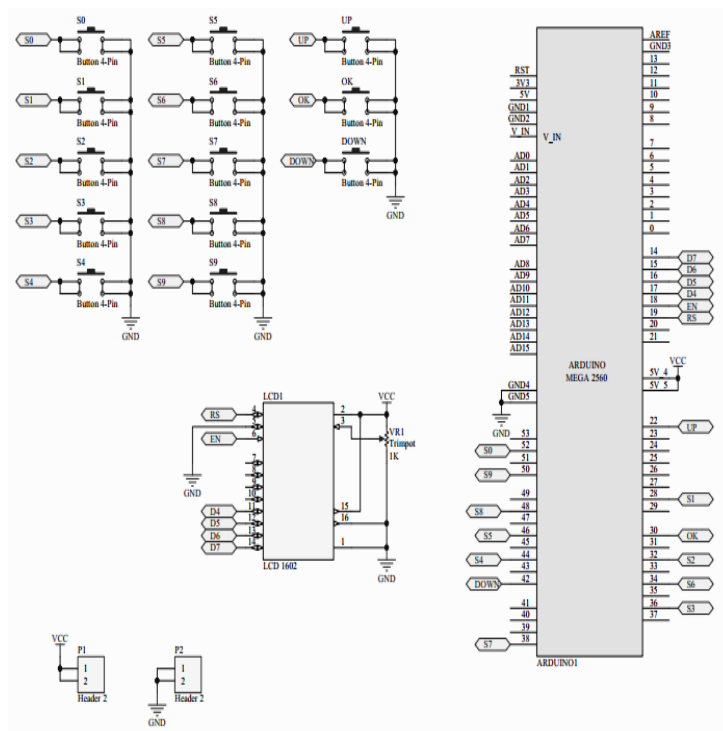

Gambar 2. Skema Panel Kendali
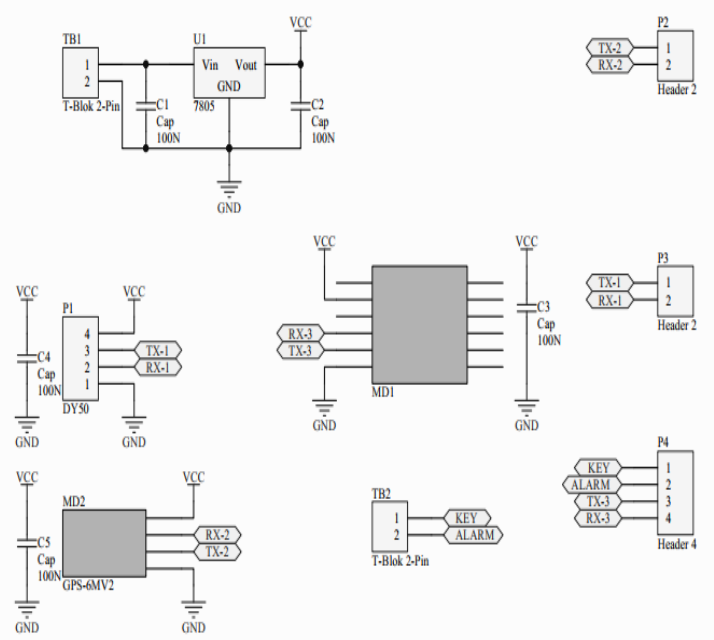

Gambar 3. Skema Modul Komunikasi

Perangkat kendali pada sistem ini menggunakan Arduino Mega 2560. Dengan menggunaka Arduino Mega 2560 sudah cukup untuk kontrol fingerprint dan gprs. Selain itu alat ini juga disertai dengan kode numerik yang membutuhkan cukup banyak pin digital Arduino dalam perancangannya, maka dari itu Arduino mega layak untuk digunakan sebagai kendali.
Gambar 3 merupakan skema rangkaian modul komunikasi. Modul komunikasi dirancang dengan menggunakan beberapa module sehingga perlu untuk merancang beberapa module tersebut menjadi saling berkomunikasi atau terhubung. Pada alat ini beberapa module tersebut disatukan dalam sebuah pcb yang nantinya terpasang bertumpukan dengan Board Arduino. Dengan demikian dapat mempermudah dalam pembuatan boks.

Setelah skema rangkaian dirancang maka dilanjutkan dengan membuat Layout PCB. Pembuatan layout pcb panel kontrol adalah pemindahan gambar skematik rangkaian menjadi skematik rangkaian pada pcb. Gambar 4 merupakan layout PCB panel kendali dan Gambar 5 adalah layout PCB modul komunikasi.

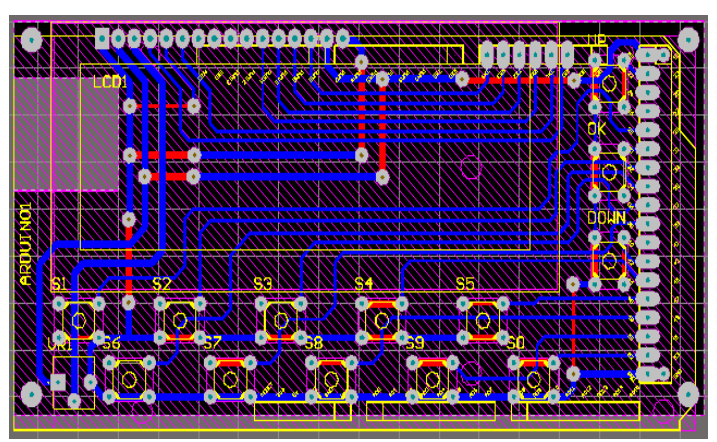

Gambar 4. Layout PCB Panel Kontrol

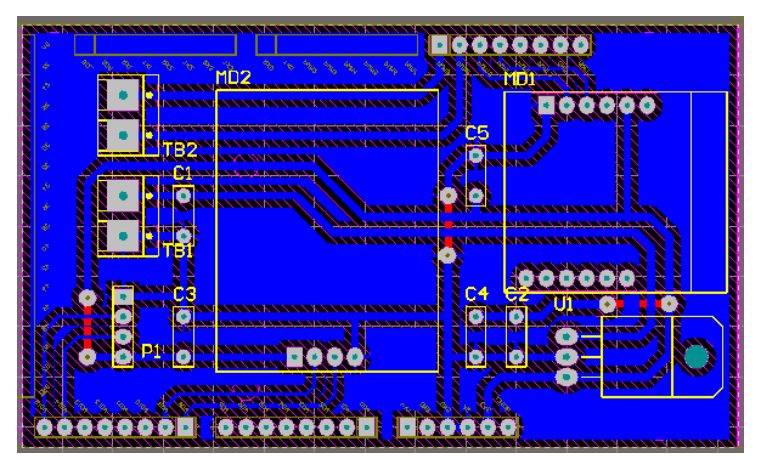

Gambar 5. Layout PCB Modul Komunikasi

Perancangan selanjutnya adalah perancangan desain 3d PCB. Langkah tersebut dilakukan untuk mempermudah dalam pemasangan komponen panel kontrol serta perancangan alat dalam bok packaging untuk di finishing. Gambar 6 dan Gambar 7 merupakan desain 3D PCB yang dihasilkan untuk panel kendali dan modul komunikasi. 


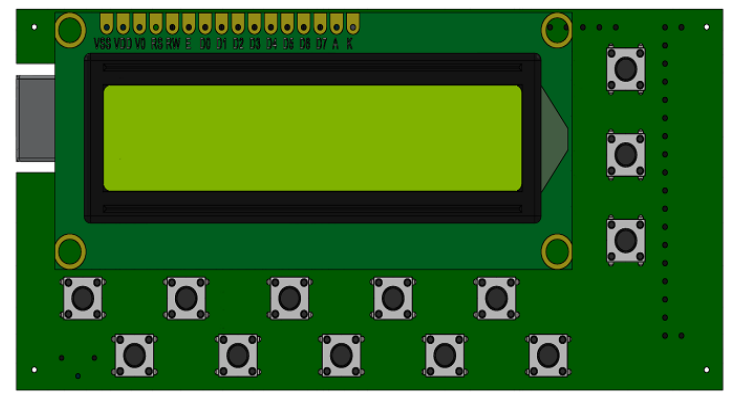

Gambar 6. Desain 3d PCB Panel Kontrol

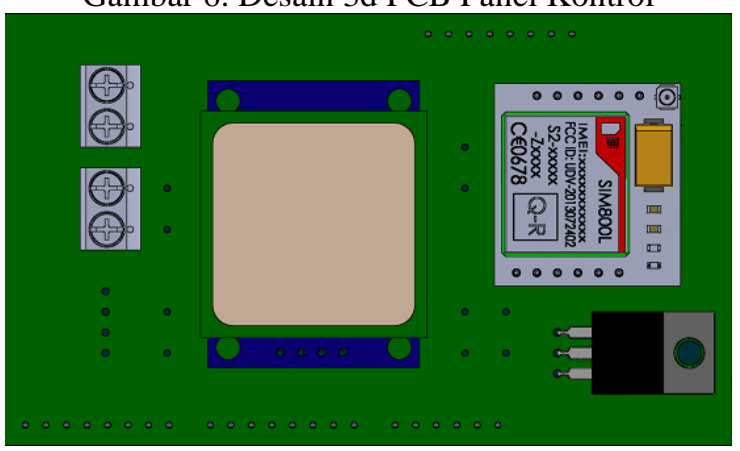

Gambar 7. Desain 3d PCB Modul Komunikasi.

Tahapan perancangan selanjutnya adalah perancangan boks agar membuat alat menjadi menarik dan mudah dipasang di sepeda motor. Hal ini dilaksanakan untuk mempermudah dalam penggabungan pcb panel kontrol, board arduino, serta pcb modul komunikasi yang nantinya akan dikemas dalam bok packaging. Gambar 8 merupakan hasil perancangan boks pengemasan sistem keamanan sepeda motor yang dikembangkan.

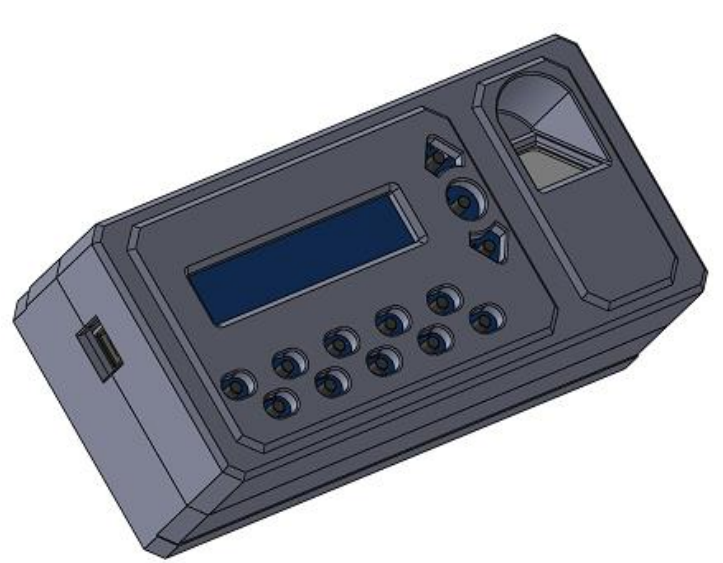

Gambar 8. Boks

Pada perancangan perangkat lunak ini, dibutuhkan rancangan pembuatan yang baik. Diagram alur digunakan untuk menggambarkan terlebih dahulu apa yang harus dikerjakan sebelum memulai membuat suatu sistem. Algoritma diagram alur tersebut diawali dengan mulai, lalu menghidupkan kontak. Apabila sepeda motor dipakai pribadi, maka mode pribadi ON. Selanjutnya sensor membaca datas sidik jari. Apabila sidik jari dikenal relay ON, maka motor dapat dinyalakan. Apabila sidik jari tidak dikenal, mengulang tiga kali. Apabila masih gagal Alarm ON (menyala) dan Motor OFF (mati). Apabila sepeda motor dipinjam, maka mode tamu ON. Apabila sidik jari peminjam (tamu) dikenal input kode angka. Apabila sidik jari tamu tidak dikenal, simpan sidik jari. Konfirmasi sidik jari dengan melakukan input kode angka. Apabila kode angka benar Relay ON, motor dapat dinyalakan. Apabila kode angka salah, mengulang tiga kali. Apabila masih gagal Alarm ON (menyala) dan Motor OFF (mati). Kinerja sistem selesai. Diagram alir secara lengkap disajikan pada Gambar 9.

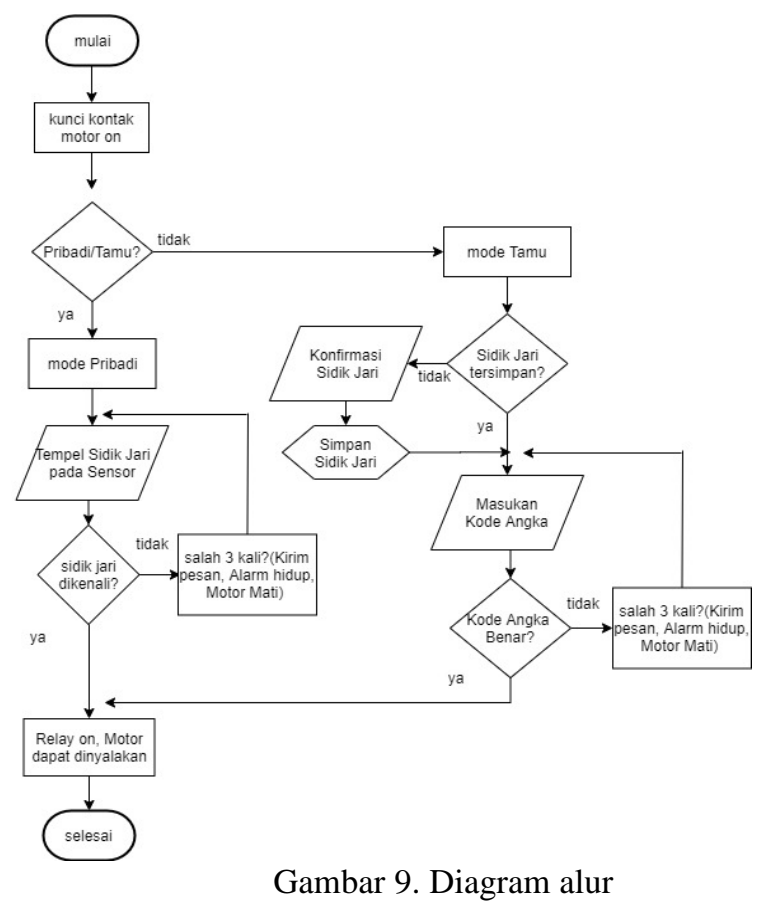

Setelah perancangan dilakukan, maka tahap penyelesaian diawali dengan realisasi perancangan. Setelah direalisasikan, perangkat diujicoba. Uji coba alat ini dilakukan untuk mengetahui kinerja Sistem Keamanan Ganda Sepeda Motor Dengan Fingerprint dan GPRS 
berbasis Arduino, untuk peningkatan keamanan. Pengambilan data dilakukan dengan cara mengamati unjuk kerja dari beberapa hal, diantaranya adalah penggunaan teknologi fingerprint, kode numerik, LCD dan GPRS module SIM800L serta kinerja alat secara keseluruhan. Tabel 1 merupakan hasil pengujian fungsional perangkat. Tabel 2 merupakan hasil pengujian tegangan dan arus perangkat.

Tabel 1. Pengujian fungsional perangkat

\begin{tabular}{lll}
\hline No & Perangkat & Hasil Uji \\
\hline 1 & Tegangan dan Arus & Baik \\
2 & Fingerprint & Berfungsi \\
3 & Kode Numerik & Berfungsi \\
4 & GPRS & Berfungsi \\
5 & LCD & Berfungsi \\
6 & Sistem perangkat secara & Berfungsi \\
& keseluruhan & \\
\hline
\end{tabular}

Tabel 2. Pengujian tegangan dan arus perangkat

\begin{tabular}{lll}
\hline No & Perangkat & Hasil Uji \\
\hline 1 & Aki & $12 \mathrm{Vdc}$ \\
2 & LM 7805 & $5 \mathrm{Vdc} / 1 \mathrm{~A}$ \\
3 & Input Relay ke kontak & $5 \mathrm{Vdc} / 0.05 \mathrm{~A}$ \\
4 & Input Relay ke Alarm & $5 \mathrm{Vdc} / 0.05 \mathrm{~A}$ \\
5 & Kontak & $12 \mathrm{Vdc} / 0.175 \mathrm{~A}$ \\
6 & Alarm & $12 \mathrm{Vdc} / 0.175 \mathrm{~A}$ \\
\hline
\end{tabular}

Berdasarkan hasil uji coba diatas, maka dapat mengetahui bahwa aki masih dalam kondisi normal. Aki yang dipakai pada sepeda motor ini memiliki kapasitas 12v/7ah/10hr artinya jika aki dipakai habis dalam kurun 10 jam kapasitasnya adalah 7Ah, Namun jika dipakai kurang dari 10 jam maka nilainya kurang dari 7Ah. LM 7805 pada alat ini mengeluarkan Output tegangan sebesar $5 \mathrm{Vdc}$ serta Arus sebesar 1A. sedangkan Relay memiliki input tegangan yang berasal dari Output Arduino sebesar 5Vdc serta Arus sebesar 0.05A. Ketika sepeda motor dalam kondisi siap dinyalakan kotak memiliki kapasitas tegangan sebesar 12 Vdc serta Arus sebesar 0.175A. ketika alarm pada kondisi menyala alarm memiliki kapasitas tegangan sebesar $12 \mathrm{Vdc}$ serta Arus sebesar 0.175A. Pengujian berikutnya adalah pengujian sensor sidik jari yang disajikan pada Tabel 3.
Tabel 3. Uji coba Fingerprint

\begin{tabular}{cccc}
\hline No. & Data sidik jari & $\begin{array}{c}\text { Hasil yang } \\
\text { diharapkan }\end{array}$ & $\begin{array}{c}\text { Hasil } \\
\text { sebenarnya }\end{array}$ \\
\hline 1. & Ibu Jari & 1 & 1 \\
2. & Jari Telunjuk & 0 & 0 \\
3. & Jari Tengah & 0 & 0 \\
4. & Jari Manis & 0 & 0 \\
5. & Jari Klingking & 0 & 0 \\
\hline
\end{tabular}

Tabel 3 menunjukkan bahwa sensor sidik jari dapat bekerja dengan baik. Dalam uji coba tersebut sidik jari yang di simpan pada alat adalah data sidik jari Ibu Jari sehingga selain menggunakan Ibu Jari, sensor tidak dapat mendeteksi data sidik jari. Sensor sidik jari R305 atau fingerprint dalam Smart Security ini dapat bekerja dengan baik. fingerprint dapat membaca sidik jari pemilik sepeda motor yang sudah tersimpan dalam sistem. Gambar 10 menunjukkan terdeteksinya sidik jari. Gambar tersebut memperlihatkan bahwa sensor sidik jari mendeteksi sidik jari pada ID 1. Sensor sidik jari pada sistem ini tidak dapat mendeteksi sidik jari yang belum tersimpan pada sistem, sehingga selain pemilik sepeda motor ini tidak ada yang bisa menyalakan motor menggunakan sidik jari.

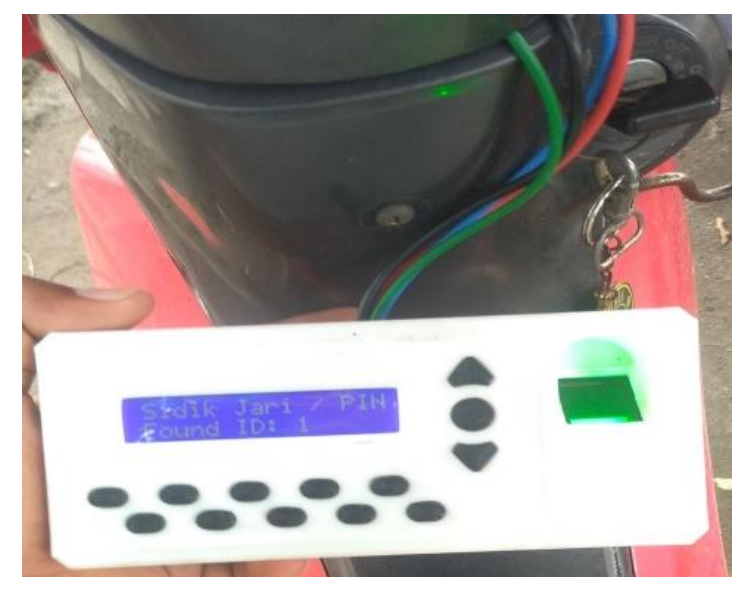

Gambar 10. Sidik jari terdeteksi

Pada Sistem keamananan sepeda motor ini penulis merancang sendiri Sistem Kode Numerik agar mempermudah dalam mendesain penampilan alat. Dalam alat ini Kode Numerik dapat bekerja dengan baik, hal ini dibuktikan pada Gambar 11. 


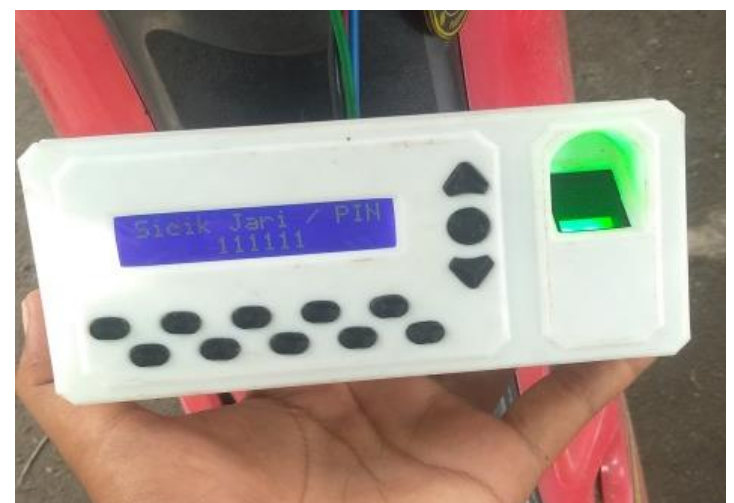

Gambar 11. Masukan kode pin (angka numerik)

Pada sistem terdapat 13 tombol yaitu tombol 0-9 yang terpasang mendatar pada bawah LCD serta tombol Up Down OK yang terpasang menurun di sebelah kanan LCD. SIM 800L pada Smart Security ini berfungsi sebagai keamanan ganda dari alat ini. Ketika alat mendeteksi ada seseorang yang mencoba menyalakan sepeda motor tetapi gagal, alat akan mengirim pesan ke smartphone pemilik sepeda motor. Pada alat ini module SIM 800L dapat berfungsi dengan baik. Gambar 12 merupakan bukti pengiriman pesan tersebut.

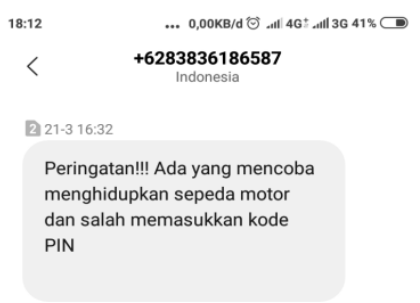

Gambar 12. Bukti Pengiriman pesan

Pada sistem ini proses pengiriman pesan terdapat delay sehingga pengiriman pesan harus menunggu. Hal ini disebabkan oleh beberapa faktor salah satunya adalah kartu perdana yang terpasang pada module SIM 800L. Selain itu module SIM 800L ini menggunakan jaringan satelit sehingga pada waktu kita berada diluar ruangan dan didalam ruangan ada perbedaan. Pada Smart Security ini LCD dapat berfungsi dengan baik. Alat ini menggunakan LCD 16 x 2 dengan led berwarna biru. Gambar 13 menunjukkan tampilan LCD.

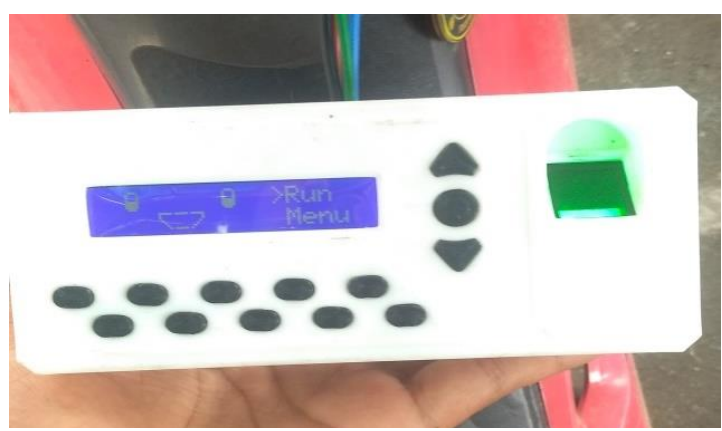

Gambar 13. LCD tampilan awal

Ketika sepeda motor dijalankan LCD terkadang kedap - kedip hal ini disebabkan sumber tegangan yang tidak setabil. Hal ini dapat diatasi dengan memberi pendinggin pada sumber tegangan alat sehingga IC regulator dapat seteril dan bekerja dengan baik sehingga LCD aman. Secara keseluruhan sistem alat dapat bekerja dengan baik sesuai dengan fungsinya. Gambar 14 dan 15 memperlihatkan berfungsinya fingerprint, GPRS, dan seluruh bagian alat yang terpasang pada sepeda motor.

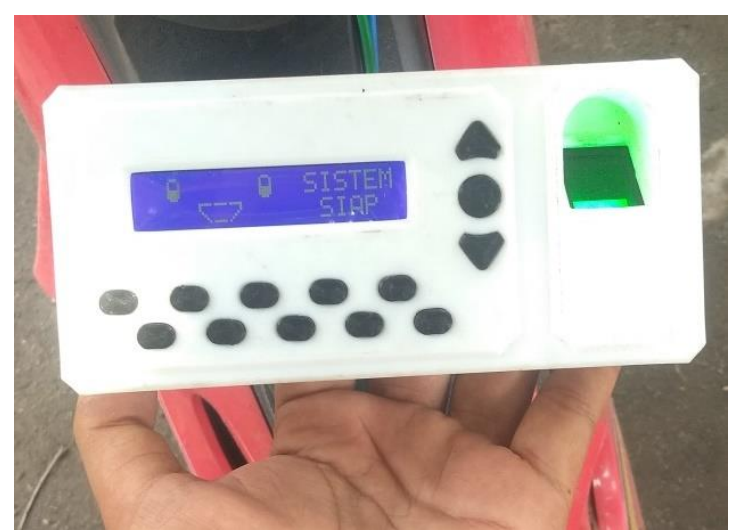

Gambar 14. LCD menampilkan tulisan Sistem Siap

Ketika uji coba 1 sepeda motor mengalami kendala, sepeda motor tidak dapat menempuh jarak jauh. Masalah ini terjadi karena kontroler alat terlalu overheat yang menyebabkan kontroler tidak dapat berfungsi dengan maksimal. Hal ini dapat diatasi dengan menambah pendingin pada bok kontroler alat. Setelah ditambah pending alat kembali diuji coba, hasilnya sepeda motor dapat menempuh jarak jauh dan dapat dipakai kemana saja. 


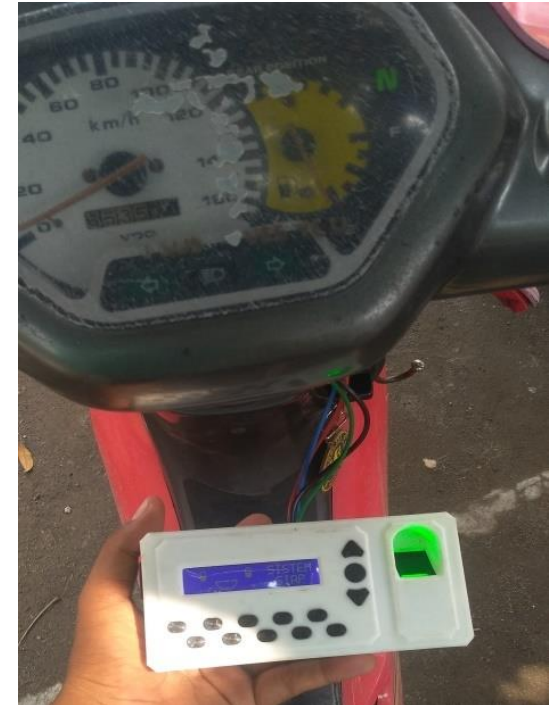

Gambar 15. N pada Spidometer menyala tanda sepeda motor siap dinyalakan

Selain itu kontroler pada alat ini terhubung melalui jalur PCB yang sudah dibuat. Jalur PCB memiliki batasan arus maksimal ketika arus melebihi batas maksimal jalur pcb, maka jalur pcb menjadi overheat hal ini juga dapat menjadi kendala motor tidak dapat menempuh jarak jauh. Hal ini dapat diatasi dengan menggunakan kabel karena kabel biasanya terbuat dari campuran tembaga dengan logam lain sehingga lebih tahan panas sedangkan jalur PCB murni terbuat dari tembaga.

Upaya preventif pencurian sepeda motor dapat diupayakan melalui sistem keamanan yang dikembangkan. Pembeda dengan pengembangan sistem keamanan yang dirujuk pada artikel ini adalah identifikasi peminjam (tamu) menggunakan keypad. Hal tersebut dikarenakan, peminjaman sepeda motor lumrah dilakukan. Pengembangan selanjutnya terkait sistem keamanan untuk mendukung upaya represif, khususnya terkait pelacakan sepeda motor yang dirampas pencuri. Sistem pengaman sepeda motor ke depan dapat dikombinasikan antara upaya preventif dan represif. Hal tersebut seperti yang dikembangkan oleh Andesta \& Ferdian yang mengembangkan sistem pengamanan sepeda motor pada saat terparkir dan perampasan di jalan (mode parkir dan mode jalan) [18]. Akan tetapi, komunikasi yang digunakan masih pesan singkat (SMS). Ke depan aplikasi lanjutan perlu diintegrasikan dengan jangkauan yang lebih luas, misalnya dengan pihak kepolisian. Optimalisasi ponsel pintar dapat menjadi alternatif perangkat telekomunikasi yang digunakan. Penggunaan ponsel pintar pada sistem pengaman sepeda motor sudah dilakukan [10][13] [16] [18]. Perlu dikaji lagi, optimalisasi ponsel pintar yang tepat untuk mendukung upaya preventif dan represif sekaligus. Hal tersebut, agar pengembangan sistem keamanan sepeda motor lebih bermanfaat.

\section{SIMPULAN}

Upaya preventif dari pencurian sepeda motor berupa pengembangan sistem keamanan sepeda motor dengan sistem otentikasi berupa sidik jari dan notifikasi pesan singkat dengan modul GPRS berhasil direalisasikan. Dari pengujian dan pembahasan alat sistem keamanan ganda sepeda motor dengan fingerprint dan gprs berbasis arduino untuk peningkatan keamanan dapat diambil simpulan: (1) Sistem Pengaman Kendaraan dapat dirancang dengan Arduino Mega 2560 dengan menggunakan sensor sidik jari dan GPRS. Sensor sidik jari pada alat ini berfungsi sebagai keamanan utama serta gprs sebagai keamanan kedua. Sensor sidik jari pada sistem Pengaman Kendaraan menjadi keamanan utama yang susah dibobol, sedangkan GPRS dapat mengirim pesan ke Android apabila kode numerik pada alat ada yang mencoba-coba tetapi gagal; dan (2) Unjuk kerja dari sistem keamanan ganda sepeda motor dengan fingerprint dan gprs berbasis arduino untuk peningkatan keamanan berdasarkan hasil pengujian dapat berfungsi dengan baik berdsarkan hasil pengiriman data dari fingerprint ke Arduino, pengiriman pesan ke Android, kode numerik mengirim data ke Arduino, serta LCD dapat menampilkan data kiriman Arduino. Saran untuk perbaikan sistem keamanan sepeda motor selanjutnya adalah: (1) pengiriman pesan ke Android dapat ditambahkan unsur-unsur yang lebih banyak; dan (2) menggunakan mikrokontroller yang memiliki spesifikasi lebih tinggi, sehingga dapat memperlancar kerja sistem pada sistem 
keamanan. Pengembangan selanjutnya perlu meninjau kebutuhan upaya preventif dan represif pada sistem pengaman sepeda motor yang dapat diintegrasikan dengan ponsel pintar agar pemanfaatan aplikasi lebih luas jangkauan pemanfaatannya.

\section{DAFTAR PUSTAKA}

[1] P. Priyambodo, "Analisis Korelasi Jumlah Kendaraan dan Pengaruhnya Terhadap PDRB di Provinsi Jawa Timur," War. Penelit. Perhub., vol. 30, no. 1, p. 59, Jul. 2018.

[2] C. W. Wijayanti, "Citra Mahasiswa Menggunakan Kendaraan: Studi Fenomenologi Mahasiswa UNS dalam Membangun Citra Menggunkaan Kendaraan Sepeda Motor," $J$. Anal. Sosiol., vol. 6, no. 2, pp. 91-106, 2017.

[3] B. S. Indonesia, "Perkembangan Jumlah Kendaraan Bermotor Menurut Jenis, 19492018," Badan Pusat Statistik, 2020. [Online]. Available:

https://www.bps.go.id/linkTableDinamis/view/i $\mathrm{d} / 1133$.

[4] S. R. M. Purba, "Upaya polisi dalam penanggulangan tindak pidana pencurian sepeda motor di wilayah hukum Kepolisian Resort Sleman," Universitas Atma Jaya Yogyakarta, 2016.

[5] S. S. P. dan Keamanan, Statistik Kriminal 2019. Jakarta: Badan Pusat Statistik, 2019.

[6] A. Ali and Z. Lukman, "Faktor-Faktor Dan Upaya Penanggulangan Tindak Pidana Pencurian Sepeda Motor (Studi Kasus Polresta Banda Aceh)," J. Justisia J. Ilmu Hukum, Perundang-undangan dan Pranata Sos., vol. 4, no. 1, p. 23, Dec. 2019.

[7] M. Ono, "Penanggulangan Kejahatan Pencurian Kendaraan Bermotor Di Kota Palu," Tadulako Master Law J., vol. 2, no. 1, pp. 63-75, 2019.

[8] E. Hartanto, "Kebijakan kriminal terhadap pencegahan pencurian kenderaan bermotor (studi di kepolisian sektor sunggal)," USU Law J., vol. 3, no. 1, pp. 101-112, 2015.

[9] Y. Purnomo and J. Hafidz, "Tinjauan yuridis terhadap pencurian sepeda motor di kabupaten Grobongan (Studi kasud Polres Grobogan)," in Prosiding Komferensi Ilmiah Mahasiswa Unissula (KIMU) 2, 2019, pp. 592-603.

[10]T. Juwariyah, D. Widiyanto, and $S$. Sulasmingsih, "Purwa Rupa Sistem Pengaman Sepeda Motor Berbasis IoT (Internet of Things)," J. Otomasi Kontrol dan Instrumentasi, vol. 11, no. 1, p. 49, May 2019.

[11]A. M. Syafar, "Perancangan sekuriti sistem kendaraan motor dengan teknologi near field communication (NFC)," J. Instek, vol. 2, no. 2, pp. 130-139, 2017.
[12]W. W. I. W. Jusoh, K. A. M. Annuar, S. H. Joharia, I. M. Saadon, and M. H. Harun, "Motorcycle Security system using GSM and RFID," J. Adv. Res. Appl. Mech., vol. 16, no. 1, pp. 1-9, 2015.

[13] Y. Normawan and H. Supriyono, "Keamanan sepeda motor berbasis kunci rahasia aplikasi android dan sistem mikroprosesor," J. Emit., vol. 19, no. 1, pp. 1-5, 2019.

[14]D. I. Prasetya and M. Mushlihudin, "Sistem Keamanan Sepeda Motor Menggunakan Kata Sandi Berbasis Arduino Nano," J. Ilm. Tek. Elektro Komput. dan Inform., vol. 4, no. 1, p. 11, Jun. 2018.

[15]F. Napitupulu, E. Kurniawan, and Cahyantari Ekaputri, "Desain dan implementasi sistem keamanan sepeda motor berbasis mikrokontroller," e-Proceeding Eng., vol. 4, no. 2, pp. 1449-1456, 2017.

[16]D. E. Kurniawan and M. N. Surur, "Sistem Pengaman Sepeda Motor Berbasis Perangkat Bergerak dengan Notifikasi dan Kendali Mesin," J. Sist. Inf., vol. 1, no. 2017, pp. 1159-1165, 9AD.

[17]K. D. Artika, "Rancang bangun sistem pengaman pada sepeda motor dengan memanfaatkan sensor encoder dan sensor ping," ROTOR, vol. 6, no. 1, 2013.

[18]D. Andesta and R. Ferdian, "Sistem Keamanan Sepeda Motor Berbasis Mikrokontroler dan Modul GSM," J. Inf. Technol. Comput. Eng., vol. 2, no. 02, pp. 51-63, Sep. 2018.

[19] M. M. Thoyyib, "Sistem keamanan sepeda motor dari perampasan menggunakan SMS dan GPS berbasis arduino uno," Universitas Negeri Yogyakarta, 2017.

[20]Y. P. Putra and Edidas, "Pengembangan Sistem Keamanan Sepeda Motor Mengggunakan Arduino Uno Berbasis Smartphone Android," J. Vocat. Tek. Elektron. dan Inform., vol. 8, no. 1, 2020.

[21]Malathi R. and Jeberson Retna Raj R., “An Integrated Approach of Physical Biometric Authentication System," Procedia Comput. Sci., vol. 85, pp. 820-826, 2016.

[22]S. R. Department, "Smartphone users in Indonesia 2015-2025," Statista, 2020. [Online]. Available:

https://www.statista.com/statistics/266729/smar tphone-users-in-indonesia/.

[23]T. Bobbe, J. Krzywinski, and C. Woelfel, "A comparison of design process models from academic theory and professional practice," in International Design Conference - Design, 2016, pp. 1205-1214. 